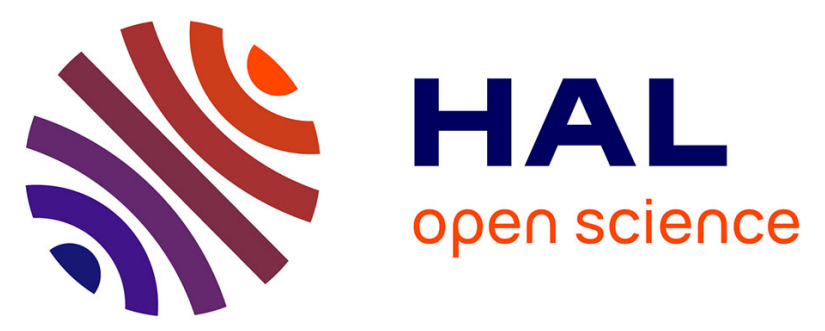

\title{
Transient Increase in Intrahepatic Pressure Mediates Successful Treatment of the Gunn Rat with Reduced Doses of Lentiviral Vector
}

Françoise Schmitt, Maude Flageul, Anne Dariel, Virginie Pichard, Cecilia Pontes, Sébastien Boni, Guillaume Podevin, Anne Myara, Nicolas Ferry, Tuan

Nguyen

\section{To cite this version:}

Françoise Schmitt, Maude Flageul, Anne Dariel, Virginie Pichard, Cecilia Pontes, et al.. Transient Increase in Intrahepatic Pressure Mediates Successful Treatment of the Gunn Rat with Reduced Doses of Lentiviral Vector. Human Gene Therapy, 2010, 21 (10), pp.1349 - 1356. 10.1089/hum.2009.220 . hal-03268900

\section{HAL Id: hal-03268900 \\ https://univ-angers.hal.science/hal-03268900}

Submitted on 23 Jun 2021

HAL is a multi-disciplinary open access archive for the deposit and dissemination of scientific research documents, whether they are published or not. The documents may come from teaching and research institutions in France or abroad, or from public or private research centers.
L'archive ouverte pluridisciplinaire HAL, est destinée au dépôt et à la diffusion de documents scientifiques de niveau recherche, publiés ou non, émanant des établissements d'enseignement et de recherche français ou étrangers, des laboratoires publics ou privés. 


\title{
Transient Increase in Intrahepatic Pressure Mediates Successful Treatment of the Gunn Rat with Reduced Doses of Lentiviral Vector
}

\author{
Françoise Schmitt, ${ }^{1,2}$ Maude Flageul,, Anne Dariel,,2 Virginie Pichard, Cecilia Abarrategui Pontes, \\ Sébastien Boni, Guillaume Podevin,, ${ }^{1,2}$ Anne Myara, ${ }^{3}$ Nicolas Ferry, ${ }^{1 *}$ and Tuan Huy Nguyen ${ }^{1 *}$
}

\begin{abstract}
Lentiviral vectors can stably transduce hepatocytes and are promising tools for gene therapy of hepatic diseases. Although hepatocytes are accessible to blood-borne viral vectors through fenestrations of the hepatic endothelium, improved liver transduction after delivery of vectors to the blood stream is needed. As the normal endothelial fenestration and lentiviral vectors are similar in size $(150 \mathrm{~nm})$, we hypothesized that a transient increase in hepatic blood pressure may enhance in vivo gene transfer to hepatocytes. We designed a simple surgical procedure, by which the liver is temporarily excluded from blood flow. Lentiviral vectors were injected in a large volume to increase intrahepatic pressure. We demonstrated that in the Gunn rat, a model of CriglerNajjar disease, the administration of low vector doses (corresponding to a multiplicity of infection of 0.2) by this procedure resulted in therapeutic correction of hyperbilirubinemia, without toxicity. The correction was sustained for 10 months (end of study). The same vector amounts yielded only partial correction after intraportal delivery. We believe that this new and clinically applicable strategy may broaden the range of genetic liver diseases accessible to gene therapy.
\end{abstract}

\section{Introduction}

$\mathrm{C}$ RIGLER-NAJJAR TYPE I (CN-I) DISEASE is a rare and severe inherited hepatic disease, characterized by a high serum level of unconjugated bilirubin. It is caused by a complete deficiency of hepatic uridine diphosphate glucuronosyltransferase isoform 1A1 (UGT1A1) activity, the enzyme responsible for the conjugation of bilirubin to two molecules of glucuronic acid. Unconjugated bilirubin is a highly hydrophobic compound that cannot be eliminated in the bile and accumulates in various organs, including the brain. Jaundice is the hallmark of this disease, but the severity of the condition is due to severe neurological damage of the brain (referred to as kernicterus) that may happen at any time during the course of the disease. Patients with CN-I are usually treated by prolonged daily sessions of phototherapy under blue light, which cause degradation of the bilirubin moiety. However, such sessions are time-consuming (up to $14 \mathrm{hr} /$ day) and are not easily compatible with a normal life. The only curative treatment is orthotopic liver transplantation. However, a shortage of donor livers and life-long immunosuppression, which is not completely devoid of secondary effects, leaves ample space for alternative therapies.

$\mathrm{CN}-\mathrm{I}$ is genetically well characterized. It does not affect the liver histology, and there is an available animal model, the Gunn rat, which mimicks the human condition. For all of these reasons, $\mathrm{CN}-\mathrm{I}$ represents a paradigm for gene therapy of inherited liver diseases. The complete cure of such diseases requires long-term expression of the transgene in a sufficient number of hepatocytes. During the past two decades, numerous studies have documented the proof-ofprinciple of gene therapy for CN-I in the Gunn rat. Various vector types have been evaluated in this model and promising results have been obtained with high-capacity adenoviral vectors or adeno-associated viral (AAV) vectors in adult animals (Toietta et al., 2005; Seppen et al., 2006). Oncoretroviral vectors are able to integrate into the genome of infected cells and are, therefore, attractive tools to drive

\footnotetext{
${ }^{1}$ INSERM U948, CHU Hôtel Dieu, 44093 Nantes Cedex, France.

${ }^{2}$ Service de Chirurgie Pédiatrique, CHU Hôtel Dieu, 44093 Nantes Cedex, France.

${ }^{3}$ Service de Biologie, Groupe Hospitalier Saint Joseph, 75014 Paris, France.

${ }^{*}$ N.F. and T.H.N contributed equally to this work (co-last authors).
} 
long-term expression of the transgene. However, their efficiency is hampered by their requirement for cell division in order to efficiently transduce cells. We previously demonstrated that Moloney murine leukemia viral (MoMuLV) vectors and lentiviral vectors delivered to the newborn Gunn rat could achieve complete and permanent correction of the CN-I phenotype (Bellodi-Privato et al., 2005; Nguyen et al., 2005). In this model, hepatocytes are actively dividing at the time of infection and an immune response to the transgene is unlikely because tolerance is usually achieved in newborn animals. However, as the diagnosis of CN-I is usually not confirmed immediately after birth, gene therapy will need to target older patients. In adult Gunn rats, MoMuLV vectors can transduce hepatocytes after a partial hepatectomy has been performed to trigger cell division (Tada et al., 1998; Aubert et al., 2002). Lentiviral vectors do not require cell proliferation to integrate and express their genome in the infected cells. Therefore, lentiviral vectors could, potentially, transduce hepatocytes in the adult, nonhepatectomized liver. This has been evaluated in numerous studies, which have achieved transduction of the liver after intravenous delivery of a lentiviral vector in adult mice (Pfeifer et al., 2001; Follenzi et al., 2002; VandenDriessche et al., 2002; van Til et al., 2005). However, in these studies lentiviral transduction of hepatocytes was relatively inefficient and the majority of transduced liver cells were of nonparenchymal origin. The induction of liver regeneration, triggered by a two-thirds partial hepatectomy and/or the administration of a hepatic mitogen, was shown to dramatically stimulate hepatocyte transduction in adult mice (Park et al., 2000; Ohashi et al., 2002; Picanco-Castro et al., 2008). Consistent with these data, an impressive increase in hepatocyte transduction was observed without host manipulation when lentiviral vector was injected into young mice (3-4 weeks old), in which the liver is still actively growing, as compared with injection into older mice (Park et al., 2003).

In the rat, available data are more sparse. Promising results were reported from a study in which Long-Evans Cinnamon rats were injected systemically with lentiviral vectors (Merle et al., 2006). Cirrhosis is a hallmark of this particular rat model of human liver disease and numerous hepatocytes are dividing in the parenchyma in these animals, probably making the hepatocytes more receptive to lentiviral infection. In juvenile Gunn rats (3 weeks old), only a partial (albeit sustained) correction was achieved after delivery of lentiviral vectors at the highest vector dose (van der Wegen et al., 2006). This suggested that lentiviral transduction of hepatocytes in juvenile Gunn rats was not optimal and that a high vector dose may still be required to treat young animals, in which there is active proliferation of hepatocytes. Last, no clear data have yet been reported for the adult rat.

Another critical parameter for liver transduction is the amount of vector that is able to reach hepatocytes. Vectors can be delivered to the blood stream, from which they will reach hepatocytes through endothelial fenestrations that are present in liver sinusoids. Fenestration size has a direct influence on the in vivo transduction of hepatocytes with viral vectors such as adenoviruses, which are comparable in size to lentiviral vectors (Lievens et al., 2004). The injection of helper-dependent adenoviral vectors into the liver, after complete vascular exclusion or transient occlusion of the hepatic outflow, results in higher transduction efficiency because the viral particles are forced through the fenestrations (Brunetti-Pierri et al., 2007, 2009). This procedure allowed for the reduction of the vector dose while maintaining the transduction level. In mice, lentiviral vectors can also be administered via a hydrodynamic injection (i.e., diluted in a large volume of saline), although a comparative analysis of this procedure with simple, intravenous infusion has not been performed (Bursill et al., 2009; Deng et al., 2009). These studies have strongly suggested an advantage in using a hydrodynamic lentiviral vector injection procedure in the liver, as compared with the portal vein or other systemic injections, for treating inherited metabolic liver disorders. However, such studies have not yet been reported.

We described an original surgical approach in which lentiviral vectors were injected into liver temporarily excluded from the blood stream under high pressure (Dariel et al., 2009). In the present study, our aim was to evaluate the therapeutic efficacy of this surgical approach for correcting hyperbilirubinemia in adult Gunn rats.

To prevent a possible cellular immune response to the transgene product we inserted into the vector backbone target sequences for miR-142-3p (miR-142), which is specifically expressed in cells of the hematopoietic lineage, as was described by Brown and colleagues in mice (Brown et al., 2007).

We show here that transient occlusion, together with increased intrahepatic pressure, significantly improved lentivirus-mediated gene transfer to the liver and led to the attainment of sustained therapeutic correction of hyperbilirubinemia in the adult Gunn rat after a single administration of a low dose of vector.

\section{Materials and Methods}

\section{Animals}

Animals were housed in the animal facilities of Nantes University Medical School (Nantes, France) and received humane care according to the guidelines of the French Ministère de l'Agriculture. Male and female, homozygous (j/j) Gunn rats weighing $125 \pm 18 \mathrm{~g}$ (6-7 weeks old) were used. They were maintained under a 12-hr light cycle and fed ad libitum.

\section{Vector description and production}

The self-inactivating mTTR.hUGT1A1.WPRE.miR142T encodes the human UGT1A1 cDNA under the control of the liver-specific murine transthyretin promoter (mTTR) promoter fused to a synthetic hepatocyte-specific enhancer (Nguyen et al., 2005). It also contains four copies of a perfectly matched target sequence to miR-142, subcloned from the pCCLsin.cPPT.ET.GFP.WPRE.142T vector (Brown et al., 2006) (kindly provided by L. Naldini, San Raffaele Telethon Institute for Gene Therapy, San Raffaele Scientific Institute, Milan), downstream of the UGT1A1 expression cassette.

Vectors were produced by transient transfection into 293T cells (Bovia et al., 2003). Vector titers were determined on HeLa cells by real-time quantitative PCR. The primers used were as follows. For the gag amplicon: GAG-F, GGAGCT AGAACGATTCGCAGTTA; GAG-R, GGTTGTAGCTGTCC CAGTATTTGTC. For normalization of the amount of genomic DNA, primers specific for the $\beta$-actin gene were used: 
HB2-F, TCCGTGTGGATCGGCGGCTCCA; HB2-R, CTGCT TGCTGATCCACATCTG. A standard curve was generated with dilutions of lentiviral vector plasmid in genomic DNA extracted from HeLa cells. Vector titers were routinely 1-5 $\times 10^{9} \mathrm{HeLa} \mathrm{TU} / \mathrm{ml}$.

\section{Bone marrow cell transduction}

Bone marrow cells were isolated from the tibias and femurs of Gunn rats and cultured in X-VIVO medium (Lonza Walkersville, Walkersville, MD) supplemented with $10 \%$ fetal bovine serum (FBS), glutamine, antibiotics, and hepatocyte growth factor (HGF, $5 \mathrm{ng} / \mathrm{ml}$; R\&D Systems, Minneapolis, MN), as previously described (Wulf-Goldenberg et al., 2008). They were transduced at $5 \times 10^{6}$ cells $/ \mathrm{ml}$ for $16 \mathrm{hr}$ on the day of cell isolation, washed, and cultured for 7 days before fluorescence-activated cell-sorting (FACS) analysis.

\section{Vector administration}

All procedures were performed under isoflurane general anesthesia $(3 \%[\mathrm{v} / \mathrm{v}]$ in air). For portal vein injection, $0.3 \mathrm{ml}$ of vector solution was injected intraportally, using a 30-gauge needle, over $1 \mathrm{~min}$ and hemostasis was obtained by gentle compression at the injection site $(n=4)$.

Injection of lentiviral vector in isolated liver (LIL) was performed in five animals, as previously described (Dariel et al., 2009). Briefly, the liver was totally excluded from the systemic blood flow by clamping the hepatic afferent and efferent veins. A 22-gauge catheter was introduced into the infrahepatic vena cava and the viral supernatant was infused in a large volume $(8.9 \mathrm{ml} / \mathrm{kg}$ body weight). We verified that this volume corresponded to an intrahepatic pressure of $10 \mathrm{~cm}$ $\mathrm{H}_{2} \mathrm{O}$. This intrahepatic pressure was measured with a graduated water column linked to the catheter. The normal hepatic pressure was less than $1 \mathrm{~cm} \mathrm{H}_{2} \mathrm{O}$. After $10 \mathrm{~min}$, blood flow was restored by declamping the suprahepatic vena cava, the infrahepatic vena cava, and then the hepatic artery and portal vein. Hemostasis of the infrahepatic vena cava was obtained by gentle compression, or after $10 / 0$ suturing of the vessel.

All viral vectors were injected at a dose of $1 \times 10^{9} \mathrm{HeLa}$ $\mathrm{TU} / \mathrm{kg}$ body weight. The multiplicity of infection was calculated by assuming that the liver weight represents $5 \%$ of the body weight and that $1 \mathrm{~g}$ of liver contains $1 \times 10^{8}$ hepatocytes (Seglen, 1973; Marcos et al., 2006; SohleniusSternbeck, 2006).

Control animals underwent the LIL procedure with injection of saline instead of vector $(n=4)$. All injected animals survived the LIL or portal vein injection procedure.

\section{Liver function assays}

Blood was drawn from the retro-orbital sinus. Serum total bilirubin and alanine aminotransferases were measured in the routine biochemistry department of Nantes University Hospital. Bile was harvested by bile duct cannulation after laparotomy. The presence of monoglucuronide and diglucuronide bilirubin conjugates was assessed by alkaline methanolysis as previously described (Muraca and Blanckaert, 1983).

\section{Vector copy number quantification}

High molecular weight DNA was amplified by quantitative PCR on an ABI Prism 7000 (Applied Biosystems, Foster
City, CA), using SYBR green (Mesa Green qPCR MasterMix; Eurogentec, Seraing, Belgium). Primers specific for lentiviral vector (GAG-F and GAG-R) were as described previously. For normalization of the amount of genomic DNA, primers specific for the rat $\beta$-actin sequence were used: RB2-F, AGCCATGTACGTAGCCATCCA; and RB2-R, TCTCCGG AGTCCATCACAATG. A standard curve was constructed, using dilutions of a lentiviral plasmid in rat genomic DNA.

\section{Statistical analysis}

Statistical analysis was performed with StatXact software (Cytel, Cambridge, MA) and the Mann-Whitney exact test to compare quantitative data.

\section{Results}

Because its unwanted expression in antigen-presenting cells (APCs) can trigger an immune response to the transgene product, resulting in the clearance of transduced cells, we applied a strategy to detarget lentiviral gene expression from the hematopoietic lineage. Brown and colleagues showed that the incorporation of target sequences for the hematopoietic-specific miR-142 in lentiviral vector repressed transgene expression in APCs, resulting in sustained transgene expression in hepatocytes in mice (Brown et al., 2006, 2007). Using a lentiviral vector encoding green fluorescent protein (GFP) as a reporter, under the control of the phosphoglycerate kinase (PGK) promoter, we evaluated whether the addition of these miR-142 target sequences could repress transgene expression in rat bone marrow-derived hematopoietic cells isolated from the Gunn rat. Figure 1 shows that the proportion of GFP-positive cells, and the level of transgene expression, were drastically reduced after transduction with vectors containing the miR-142 target sequences. These results showed that the miR-142 strategy for detargeting lentiviral gene expression from hematopoietic cell lineages is effective in the Gunn rat model. We then constructed a

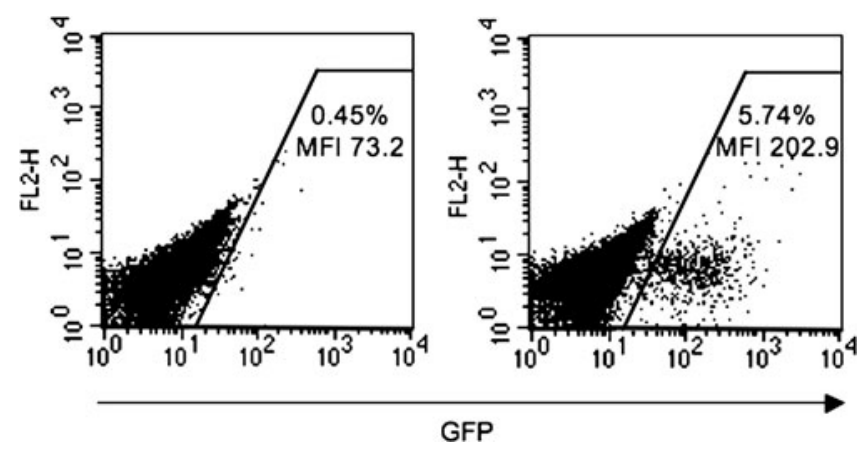

FIG. 1. Detargeting of lentiviral gene expression in rat hematopoietic cells. Gunn rat-derived bone marrow cells were transduced with lentiviral vectors encoding green fluorescent protein (GFP) under the control of the phosphoglycerate kinase (PGK) promoter carrying (left), or not (right), target sequences to miR-142, at a multiplicity of infection (MOI) of 1. On day 7 posttransduction, cells were analyzed by fluorescence-activated cell sorting (FACS). The percentage of GFP-positive cells and the mean intensity of fluorescence are indicated. MFI, mean fluorescence intensity. 


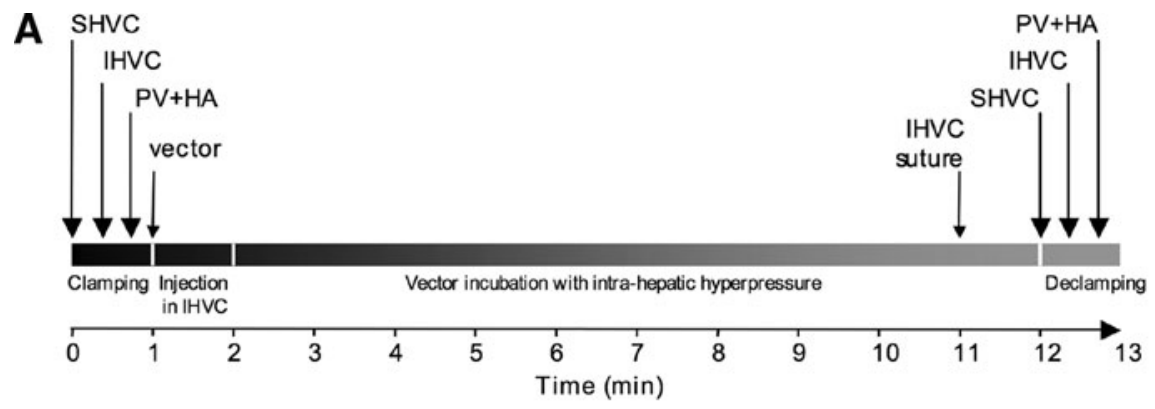

B
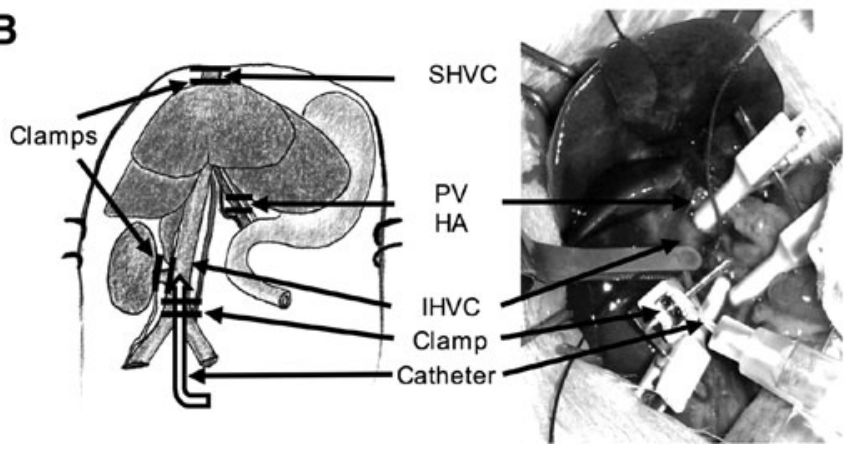

C

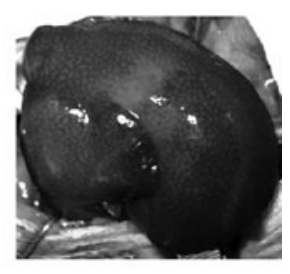

FIG. 2. Selective injection of lentiviral vectors in surgically isolated liver (LIL). (A) Experimental design showing the timing of the LIL procedure. Hemostasis of the infrahepatic vena cava (IHVC) was obtained by manual compression or suture at the site of vector injection. (B) Schematic drawing and photograph of the LIL procedure. Afferent and efferent veins of the liver, and the right adrenal vein, were exposed and clamped. After dissecting the bile duct, the portal vein (PV) and hepatic artery (HA) were selectively clamped. A catheter was placed in the IHVC for vector injection. (C) Photograph of the liver during vector incubation. The liver enlarges because of the high intrahepatic pressure. SHVC, suprahepatic vena cava. The position of the clamps is indicated by a double line. liver-specific, and miR142-regulated, lentiviral vector for the treatment of Gunn rats.

A cohort of homozygous $(\mathrm{j} / \mathrm{j})$ Gunn rats (age, 6 weeks; $n=5)$ was subjected to lentiviral injection in isolated liver (LIL; Fig. 2). Briefly, after complete exclusion of the liver from the blood flow, the infrahepatic vena cava was cannulated and lentiviral vectors were injected over $1 \mathrm{~min}$ at a dose of $8.9 \mathrm{ml} / \mathrm{kg}$ body weight. This volume contained the viral particles at a dose of $1 \times 10^{9} \mathrm{HeLa} \mathrm{TU} / \mathrm{kg}$ body weight, corresponding to a multiplicity of infection (MOI) of 0.2 (for the calculation of MOI, see Materials and Methods). This procedure resulted in visible swelling of the whole liver (Fig. $2 \mathrm{C})$. We verified that this volume corresponded to an intrahepatic pressure of $10 \mathrm{~cm} \mathrm{H}_{2} \mathrm{O}$. After $10 \mathrm{~min}$ of high pressure, blood flow was restored by declamping the afferent and efferent vessels. A control group $(n=4)$ received the same vector dose by bolus injection into the portal vein, without clamping of the afferent and efferent vessels of the liver. Sham animals underwent the complete LIL procedure, with injection of saline instead of vector $(n=4)$. The vector dose was chosen to achieve approximately $50 \%$ partial correction of hyperbilirubinemia after intraportal delivery, such that an improvement in therapeutic effect could be easily detected by measurement of the serum bilirubin level. Furthermore, this level of reduction in hyperbilirubinemia corresponded to that obtained in patients with CN-I treated by cell therapy (Fox et al., 1998).

At various time points after vector administration, blood samples were taken and serum bilirubin levels were monitored. As shown in Fig. 3, a rapid decrease in serum bilirubin occurred after 2 weeks in both portal vein-injected and LIL animals. The serum bilirubin concentration reached a plateau that remained stable for 10 months (the duration of the experiment), demonstrating the stability of the correction and the absence of an immune response to the transduced cells. The mean serum bilirubin values were consistently significantly lower in LIL animals than those observed in age- matched, noninjected controls $(p<0.05)$. Moreover, the mean serum bilirubin concentration in animals that underwent the LIL procedure during follow-up was 2-fold lower than that observed in portal vein-injected animals (Fig. 3). This difference was statistically significant $(p<0.05)$. In

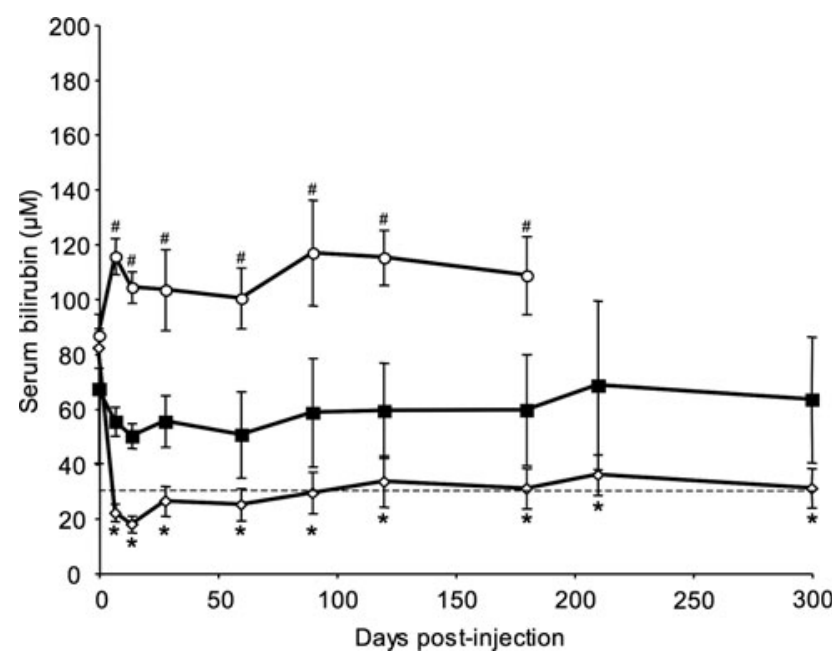

FIG. 3. Time course analysis of serum bilirubin levels in injected Gunn rats. Rats received lentiviral vectors encoding hUGT1A1 under the control of the murine transthyretin promoter (mTTR) liver-specific promoter at a dose of $1 \times 10^{9}$ $\mathrm{HeLa} \mathrm{TU} / \mathrm{kg}$ body weight. Vector solution was injected by the LIL (injection of lentiviral vector in isolated liver) procedure (open diamonds, $n=5$ ) or portal vein injection (nonisolated liver) (solid squares, $n=4$ ). A control group received saline via the LIL procedure (open circles, $n=4$ ). Each value plotted represents the mean \pm SEM. The dashed line represents the therapeutic threshold of bilirubinemia. Control rats developed severe hyperbilirubinemia. ${ }^{\#} p<0.05$ for vector-injected versus saline-injected animals; ${ }^{*} p<0.05$ for LIL-injected versus portal vein-injected animals. 
FIG. 4. Analysis of the proportion of bile derivatives in vector-injected Gunn rats. At the time of sacrifice, bile was collected and analyzed for the presence of bilirubin glucuronides by highperformance liquid chromatography (HPLC). The graph represents the proportions of bile derivatives after portal vein injection or LIL (injection of lentiviral vector in isolated liver). Representative results obtained with bile from control Gunn rats and wild-type Wistar rats are also shown.

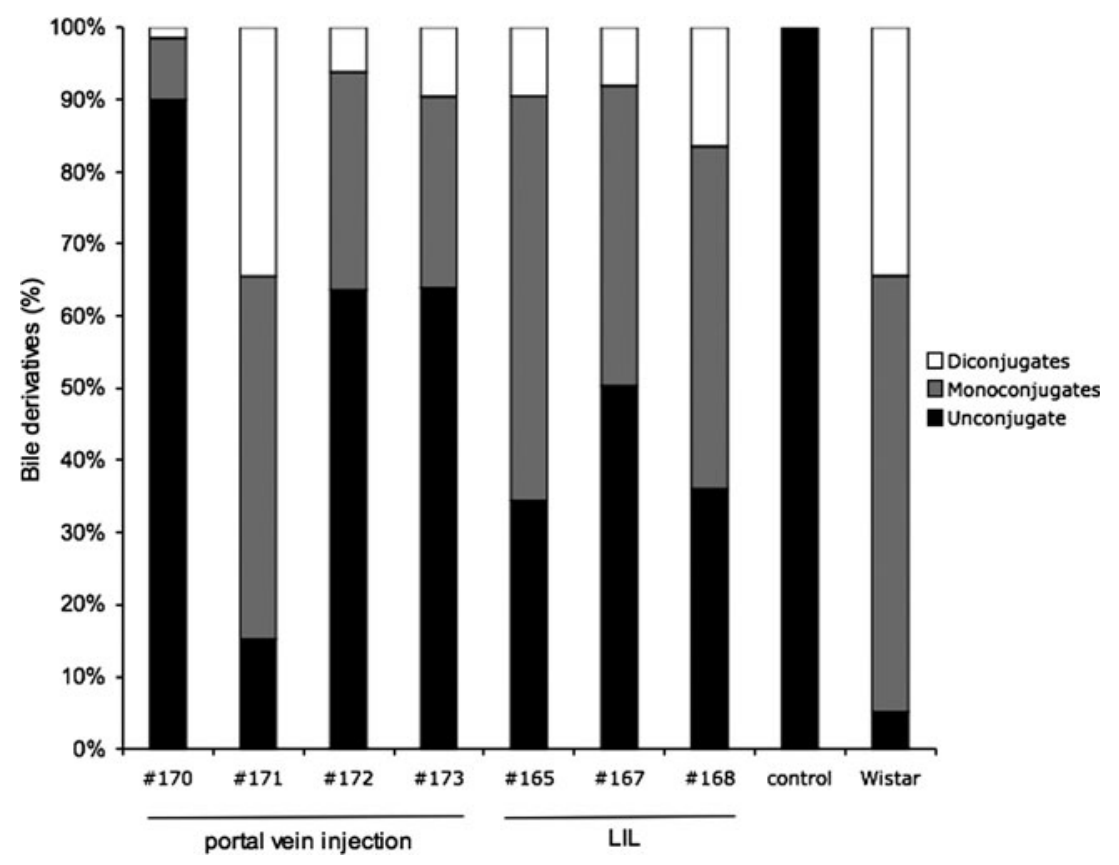

contrast, bilirubinemia increased with time and reached a plateau at about $110 \mu \mathrm{M}$ in saline-injected animals.

To detect any liver injury due to the procedure, we assessed serum levels of hepatic alanine aminotransferase (ALT) in experimental animals on day 7 after vector injection. Mean ALT values on day 7 were not significantly different from basal values recorded before vector administration for the LIL group $(0.796 \pm 0.0688$ vs. $1.264 \pm 0.508 \mu \mathrm{kat} /$ liter for day 0 and day 7 , respectively) or for the portal vein injection group $(0.6475 \pm 0.1737$ vs. $0.755 \pm 0.04 \mu \mathrm{kat} /$ liter $)$. These results confirmed the overall good tolerance of the procedure, although we cannot exclude acute liver toxicity between day 0 and day 7 in the present study.

Animals were killed on day 300 and bile and livers were harvested. Dissection of the hepatic pedicle was not possible in all animals in the LIL cohort because of the presence of strong adhesions as a result of the surgical procedure. Bile samples were recovered from three of five animals in this cohort. High-performance liquid chromatography (HPLC) analyses of bile samples revealed the presence of bilirubin mono- and diconjugate in all experimental animals (Fig. 4). The proportion of each form was not significantly different between animals that underwent the LIL procedure and those that received intraportal infusion of the vector. The presence of variable amounts of unconjugated bilirubin is in agreement with a bilirubinemia above $10 \mu \mathrm{M}$. Gunn rats do not show any bilirubin conjugation activity, due to a frameshift mutation in the UGT1A1 gene and, consequently, no bilirubin conjugates are found in the bile of these rats (Fig. 4).

We also monitored, by qPCR, the presence and amount of vector genome in high molecular weight DNA samples from liver. As shown in Fig. 5, the genome copy number was significantly higher in the LIL group than in the portal veininjected animals (4-fold increase; $p<0.05)$. This correlated with the lower serum bilirubin levels observed in the LIL-injected animals. We observed vector dissemination throughout the body outside the liver in LIL-injected animals, as well as in portal vein-injected controls. There was no significant difference between the two groups in vector copy number in the organs analyzed (lung, intestine, and kidney), with the exception of the spleen, where the vector was not detected in any of the LIL-injected animals, but was present in three of four portal vein-injected animals. Last, we observed normal liver histology in all animals at sacrifice (data not shown).

\section{Discussion}

Lentiviral vectors are promising tools for gene therapy of inherited liver disorders. This is particularly true for diseases that require treatment at a young age. Indeed, because these vectors are able to integrate their genome into the genome of

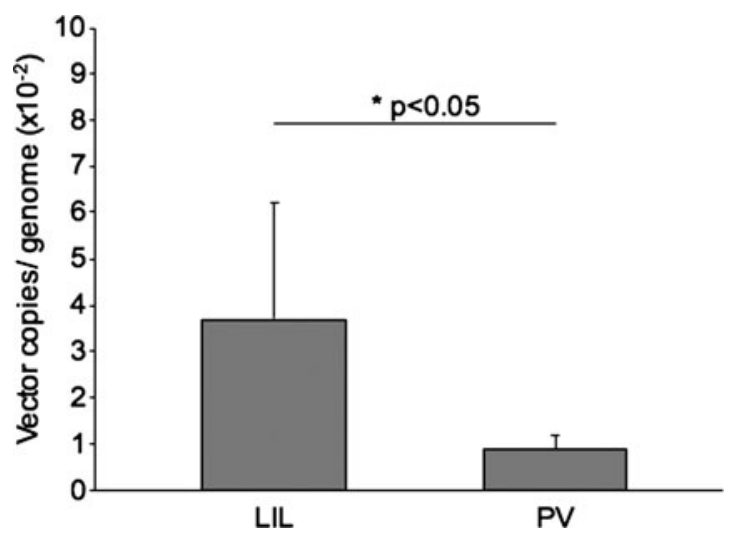

FIG. 5. Analysis of lentiviral vector content in the liver. Quantitative PCR (qPCR) analysis was performed at the time of sacrifice on liver samples from all Gunn rats treated by LIL (injection of lentiviral vector in isolated liver) or portal vein injection (PV). Values are presented as means $\pm S E M$. ${ }^{*} p<0.05$, LIL versus PV. 
infected cells, the therapeutic effect is transmitted to the progeny of dividing cells.

The liver is the largest organ in the body and, thus, represents a challenge for in vivo gene therapy, because high amounts of vector are required to yield a therapeutic effect. Injection of a high vector dose may be problematic in terms of vector production as well as for biosafety. For instance, an MOI of 5 would require the injection of about $1.4 \times 10^{12} \mathrm{TU}$ in adult patients. The aim of this study was to design a surgical approach to increase the efficiency of transduction and, therefore, to improve the therapeutic effect while using a lower dose of vector.

In vivo transduction of hepatocytes largely relies on their accessibility to blood-borne viral vectors. Vectors injected into the blood stream must cross the liver endothelium through fenestrations, and reach hepatocytes through the space of Disse. The importance of the opening of these fenestrations, which are present only in the liver, as well as of their size, has been highlighted (Jacobs et al., 2009). In rodents, the mean fenestration size is in the range of $150 \mathrm{~nm}$, which is also the mean size of lentiviral particles (Snoeys et al., 2007; Zhang et al., 2008). Therefore, any dilation of the fenestration may impact on transduction efficiency. This is particularly relevant to chronic liver diseases, during the course of which fibrosis develops. Thickening of the basal membrane in the space of Disse, together with closing of the fenestration (referred to as capillarization), severely impairs the transduction of hepatocytes by viral vectors. The administration of vasoactive compounds before adenoviral vector administration was shown to enhance the transduction of hepatocytes in a rodent model of liver cancer (Bilbao et al., 2000). Another approach has been developed for use with helper-dependent adenoviral vectors in nonhuman primates. This approach entailed the application of transient occlusion of the liver outflow to force viral vectors through the space of Disse, and resulted in a more than 10-fold increase in hepatocyte transduction, as compared with delivery via the portal vein (Brunetti-Pierri et al., 2006, 2007, 2009).

In the present report, we show that the same results can be obtained with lentiviral vectors. The induction of a $10 \mathrm{~cm}$ $\mathrm{H}_{2} \mathrm{O}$ column intrahepatic pressure resulted in a statistically significant, 4-fold increase in vector genome number per haploid genome. The vector contents detected in the liver were consistent with our previous study, in which Gunn rats were injected with GFP-encoding lentiviral vectors (Dariel et al., 2009). In this previous study, the expression of GFP, detected by immunohistochemistry, revealed $10 \%$ transduction efficiency in the liver of LIL-injected animals at the same vector dose that we used here.

Similarly, there was a concomitant, statistically significant increase in the therapeutic effect, and in rats subjected to LIL, serum bilirubin levels reached a therapeutic threshold $(30 \mu M)$. It is noteworthy that the vector dose used in our study was about 10 -fold lower than the vector dose per body weight required to achieve a therapeutic effect in the juvenile Gunn rat and in hemophilia B mice, using lentiviral vectors (van der Wegen et al., 2006; Brown et al., 2007).

Although lentiviral vectors are known to efficiently transduce hepatocytes when freshly isolated from the liver, their in vivo administration to the liver yielded less impressive results. This discrepancy may be associated with three different issues. The first limitation, due to the endothelial fenestration size, may be solved by a transient increase in intrahepatic pressure, as shown here. Second, there is a strong, species-specific restriction of the capacity of lentiviral vectors to infect adult hepatocytes. As an example, the proportion of ex vivo-transduced hepatocytes may vary from $30 \%$ in rodents to more than $90 \%$ in humans and nonhuman primates (Nguyen et al., 2002; Giannini et al., 2003; Birraux et al., 2009; Dagher et al., 2009). This may be due to intrinsic factors of the host. Therefore, in vivo transduction of rodent hepatocytes is, theoretically, restricted to less than one-third of the liver mass. Last, the quiescence of hepatocytes in the $\mathrm{G}_{0}$ state of the cell cycle in the adult liver hampers their susceptibility to lentivirus infection. Isolation of hepatocytes from the liver, using collagenase, triggers entry into the cell cycle and a shift from the $G_{0}$ to the $G_{1}$ state. In this situation, isolated hepatocytes are fully transducible by lentiviral vectors. Although mitosis is not required for infection by lentiviral vectors, hepatocyte division induced by partial hepatectomy and/or by liver growth occurring in young animals greatly increases the transduction rate with these vectors (Park et al., 2000, 2003; Ohashi et al., 2002).

In conclusion, we have described a simple surgical procedure to improve the therapeutic effect of lentiviral vectors, which can easily be performed in small, as well as large, animal models. If we extrapolate our results, the vector dose required to treat a patient with CN-I by the LIL approach would be $5-6 \times 10^{10} \mathrm{TU}$, which is more cost-effective and realistic than the production of vector for direct intravenous vector injection $\left(1.4 \times 10^{12} \mathrm{TU}\right)$. Thus, we believe that transient blood flow occlusion and high intrahepatic pressure will help to remove one limitation of hepatic gene transfer and that it should contribute to the development of clinical trials of gene therapy for inherited liver diseases in the near future.

\section{Acknowledgments}

This work was funded by grants from the Association Française contre les Myopathies (AFM) and the Association Francophone des Glycogénoses. M.F. received a fellowship from AFM. The authors are indebted to Kate Vassaux for careful reading of the manuscript.

\section{Author Disclosure Statement}

All authors have nothing to disclose.

\section{References}

Aubert, D., Menoret, S., Chiari, E., Pichard, V., Durand, S., Tesson, L., Moullier, P., Anegon, I., and Ferry, N. (2002). Cytotoxic immune response blunts long-term transgene expression after efficient retroviral-mediated hepatic gene transfer in rat. Mol. Ther. 5, 388-396.

Bellodi-Privato, M., Aubert, D., Pichard, V., Myara, A., Trivin, F., and Ferry, N. (2005). Successful gene therapy of the Gunn rat by in vivo neonatal hepatic gene transfer using murine oncoretroviral vectors. Hepatology 42, 431-438.

Bilbao, R., Bustos, M., Alzuguren, P., Pajares, M.J., Drozdzik, M., Qian, C., and Prieto, J. (2000). A blood-tumor barrier limits gene transfer to experimental liver cancer: The effect of vasoactive compounds. Gene Ther. 7, 1824-1832.

Birraux, J., Menzel, O., Wildhaber, B., Jond, C., Nguyen, T.H., and Chardot, C. (2009). A step toward liver gene therapy: 
Efficient correction of the genetic defect of hepatocytes isolated from a patient with Crigler-Najjar syndrome type 1 with lentiviral vectors. Transplantation 87, 1006-1012.

Bovia, F., Salmon, P., Matthes, T., Kvell, K., Nguyen, T.H., Werner-Favre, C., Barnet, M., Nagy, M., Leuba, F., Arrighi, J.F., Piguet, V., Trono, D., and Zubler, R.H. (2003). Efficient transduction of primary human B lymphocytes and nondividing myeloma $B$ cells with HIV-1-derived lentiviral vectors. Blood 101, 1727-1733.

Brown, B.D., Venneri, M.A., Zingale, A., Sergi Sergi, L., and Naldini, L. (2006). Endogenous microRNA regulation suppresses transgene expression in hematopoietic lineages and enables stable gene transfer. Nat. Med. 12, 585-591.

Brown, B.D., Cantore, A., Annoni, A., Sergi, L.S., Lombardo, A., Della Valle, P., D'Angelo, A., and Naldini, L. (2007). A microRNA-regulated lentiviral vector mediates stable correction of hemophilia B mice. Blood 110, 4144-4152.

Brunetti-Pierri, N., Ng, T., Iannitti, D.A., Palmer, D.J., Beaudet, A.L., Finegold, M.J., Carey, K.D., Cioffi, W.G., and Ng, P. (2006). Improved hepatic transduction, reduced systemic vector dissemination, and long-term transgene expression by delivering helper-dependent adenoviral vectors into the surgically isolated liver of nonhuman primates. Hum. Gene Ther. 17, 391-404.

Brunetti-Pierri, N., Stapleton, G.E., Palmer, D.J., Zuo, Y., Mane, V.P., Finegold, M.J., Beaudet, A.L., Leland, M.M., Mullins, C.E., and $\mathrm{Ng}$, P. (2007). Pseudo-hydrodynamic delivery of helper-dependent adenoviral vectors into non-human primates for liver-directed gene therapy. Mol. Ther. 15, 732-740.

Brunetti-Pierri, N., Stapleton, G.E., Law, M., Breinholt, J., Palmer, D.J., Zuo, Y., Grove, N.C., Finegold, M.J., Rice, K., Beaudet, A.L., Mullins, C.E., and Ng, P. (2009). Efficient, longterm hepatic gene transfer using clinically relevant HDAd doses by balloon occlusion catheter delivery in nonhuman primates. Mol. Ther. 17, 327-333.

Bursill, C.A., McNeill, E., Wang, L., Hibbitt, O.C., Wade-Martins, R., Paterson, D.J., Greaves, D.R., and Channon, K.M. (2009). Lentiviral gene transfer to reduce atherosclerosis progression by long-term CC-chemokine inhibition. Gene Ther. 16, 93-102.

Dagher, I., Nguyen, T., Groyer-Picard, M., Lainas, P., Mainot, S., Guettier, C., Pariente, D., Franco, D., and Weber, A. (2009). Efficient hepatocyte engraftment and long-term transgene expression after reversible portal embolization in non-human primates. Hepatology 49, 950-959.

Dariel, A., Nguyen, T.H., Pichard, V., Schmitt, F., Aubert, D., Ferry, N., and Podevin, G. (2009). A new surgical approach to improve gene transfer in liver using lentiviral vectors. J. Pediatr. Surg. 44, 517-522.

Deng, L., Li, G., Xi, L., Yin, A., Gao, Y., You, W., Wang, X., and Sun, B. (2009). Hepatitis B virus inhibition in mice by lentiviral vector mediated short hairpin RNA. BMC Gastroenterol. 9, 73.

Follenzi, A., Sabatino, G., Lombardo, A., Boccaccio, C., and Naldini, L. (2002). Efficient gene delivery and targeted expression to hepatocytes in vivo by improved lentiviral vectors. Hum. Gene Ther. 13, 243-260.

Fox, I.J., Chowdhury, J.R., Kaufman, S.S., Goertzen, T.C., Chowdhury, N.R., Warkentin, P.I., Dorko, K., Sauter, B.V., and Strom, S.C. (1998). Treatment of the Crigler-Najjar syndrome type I with hepatocyte transplantation. N. Engl. J. Med. 338, 1422-1426.

Giannini, C., Morosan, S., Tralhao, J.G., Guidotti, J.E., Battaglia, S., Mollier, K., Hannoun, L., Kremsdorf, D., Gilgenkrantz, H., and Charneau, P. (2003). A highly efficient, stable, and rapid approach for ex vivo human liver gene therapy via a FLAP lentiviral vector. Hepatology 38, 114-122.
Jacobs, F., Feng, Y., van Craeyveld, E., Lievens, J., Snoeys, J., and de Geest, B. (2009). Species differences in hepatocyte-directed gene transfer: Implications for clinical translation. Curr. Gene Ther. 9, 83-90.

Lievens, J., Snoeys, J., Vekemans, K., van Linthout, S., de Zanger, R., Collen, D., Wisse, E., and de Geest, B. (2004). The size of sinusoidal fenestrae is a critical determinant of hepatocyte transduction after adenoviral gene transfer. Gene Ther. 11, 1523-1531.

Marcos, R., Monteiro, R.A., and Rocha, E. (2006). Design-based stereological estimation of hepatocyte number, by combining the smooth optical fractionator and immunocytochemistry with anti-carcinoembryonic antigen polyclonal antibodies. Liver Int. 26, 116-124.

Merle, U., Encke, J., Tuma, S., Volkmann, M., Naldini, L., and Stremmel, W. (2006). Lentiviral gene transfer ameliorates disease progression in Long-Evans cinnamon rats: An animal model for Wilson disease. Scand. J. Gastroenterol. 41, 974-982.

Muraca, M., and Blanckaert, N. (1983). Liquid-chromatographic assay and identification of mono- and diester conjugates of bilirubin in normal serum. Clin. Chem. 29, 1767-1771.

Nguyen, T.H., Oberholzer, J., Birraux, J., Majno, P., Morel, P., and Trono, D. (2002). Highly efficient lentiviral vectormediated transduction of nondividing, fully reimplantable primary hepatocytes. Mol. Ther. 6, 199-209.

Nguyen, T.H., Bellodi-Privato, M., Aubert, D., Pichard, V., Myara, A., Trono, D., and Ferry, N. (2005). Therapeutic lentivirus-mediated neonatal in vivo gene therapy in hyperbilirubinemic Gunn rats. Mol. Ther. 12, 852-859.

Ohashi, K., Park, F., and Kay, M.A. (2002). Role of hepatocyte direct hyperplasia in lentivirus-mediated liver transduction in vivo. Hum. Gene Ther. 13, 653-663.

Park, F., Ohashi, K., Chiu, W., Naldini, L., and Kay, M. (2000). Efficient lentiviral transduction of liver requires cell cycling in vivo. Nat. Genet. 24, 49-52.

Park, F., Ohashi, K., and Kay, M.A. (2003). The effect of age on hepatic gene transfer with self-inactivating lentiviral vectors in vivo. Mol. Ther. 8, 314-323.

Pfeifer, A., Kessler, T., Yang, M., Baranov, E., Kootstra, N., Cheresh, D., Hoffman, R., and Verma, I. (2001). Transduction of liver cells by lentiviral vectors: Analysis in living animals by fluorescence imaging. Mol. Ther. 3, 319-322.

Picanco-Castro, V., Fontes, A.M., Heinz, S., Tonn, T., and Covas, D.T. (2008). The chimeric cytokine Hyper-IL-6 enhances the efficiency of lentiviral gene transfer in hepatocytes both in vitro and in vivo. Biotechnol. Lett. 30, 215-220.

Seglen, P.O. (1973). Preparation of rat liver cells. 3. Enzymatic requirements for tissue dispersion. Exp. Cell Res. 82, 391-398.

Seppen, J., Bakker, C., de Jong, B., Kunne, C., van den Oever, K., Vandenberghe, K., de Waart, R., Twisk, J., and Bosma, P. (2006). Adeno-associated virus vector serotypes mediate sustained correction of bilirubin UDP glucuronosyltransferase deficiency in rats. Mol. Ther. 13, 1085-1092.

Snoeys, J., Lievens, J., Wisse, E., Jacobs, F., Duimel, H., Collen, D., Frederik, P., and de Geest, B. (2007). Species differences in transgene DNA uptake in hepatocytes after adenoviral transfer correlate with the size of endothelial fenestrae. Gene Ther. $14,604-612$

Sohlenius-Sternbeck, A.K. (2006). Determination of the hepatocellularity number for human, dog, rabbit, rat and mouse livers from protein concentration measurements. Toxicol. In Vitro 20, 1582-1586.

Tada, K., Chowdhury, N.R., Neufeld, D., Bosma, P.J., Heard, M., Prasad, V.R., and Chowdhury, J.R. (1998). Long-term reduction 
of serum bilirubin levels in Gunn rats by retroviral gene transfer in vivo. Liver Transpl. Surg. 4, 78-88.

Toietta, G., Mane, V.P., Norona, W.S., Finegold, M.J., Ng, P., McDonagh, A.F., Beaudet, A.L., and Lee, B. (2005). Lifelong elimination of hyperbilirubinemia in the Gunn rat with a single injection of helper-dependent adenoviral vector. Proc. Natl. Acad. Sci. U.S.A. 102, 3930-3935.

Vandendriessche, T., Thorrez, L., Naldini, L., Follenzi, A., Moons, L., Berneman, Z., Collen, D., and Chuah, M.K. (2002). Lentiviral vectors containing the human immunodeficiency virus type- 1 central polypurine tract can efficiently transduce nondividing hepatocytes and antigen-presenting cells in vivo. Blood 100, 813-822.

van der Wegen, P., Louwen, R., Imam, A.M., Buijs-Offerman, R.M., Sinaasappel, M., Grosveld, F., and Scholte, B.J. (2006). Successful treatment of UGT1A1 deficiency in a rat model of Crigler-Najjar disease by intravenous administration of a liver-specific lentiviral vector. Mol. Ther. 13, 374-381.

van Til, N.P., Markusic, D.M., van der Rijt, R., Kunne, C., Hiralall, J.K., Vreeling, H., Frederiks, W.M., Oude-Elferink, R.P., and Seppen, J. (2005). Kupffer cells and not liver sinusoidal endothelial cells prevent lentiviral transduction of hepatocytes. Mol. Ther. 11, 26-34.
Wulf-Goldenberg, A., Eckert, K., and Fichtner, I. (2008). Cytokine-pretreatment of $\mathrm{CD} 34^{+}$cord blood stem cells in vitro reduces long-term cell engraftment in NOD/SCID mice. Eur. J. Cell Biol. 87, 69-80.

Zhang, S., Xiao, L., Zhou, H., Yu, Z., Chen, H., Guo, A., and Jin, M. (2008). Generation and characterization of an H5N1 avian influenza virus hemagglutinin glycoprotein pseudotyped lentivirus. J. Virol. Methods 154, 99-103.

Address correspondence to: Dr. Tuan Huy Nguyen INSERM U948 Biothérapies Hépatiques CHU Hotel Dieu 44093 Nantes Cedex, France

E-mail: tuan.nguyen@univ-nantes.fr

Received for publication December 15, 2009;

accepted after revision May 14, 2010.

Published online: August 31, 2010. 